\title{
The Effects of Playing with Thin Dolls on Body Image and Food Intake in Young Girls
}

\author{
Doeschka J. Anschutz • Rutger C. M. E. Engels
}

Published online: 22 August 2010

(C) The Author(s) 2010. This article is published with open access at Springerlink.com

\begin{abstract}
This study experimentally tested the effects of playing with thin dolls on body image and food intake in 6- to 10-year-old Dutch girls $(N=117)$. Girls were randomly assigned to play with a thin doll, an average-sized doll, or Legos in a no doll control condition. After $10 \mathrm{~min}$, they participated in a taste-test and completed questionnaires about body image. No differences were found between conditions for any of the body image variables. However, girls who played with the average-sized doll ate significantly more food than girls in other exposure conditions. Although no support was found for the assumption that playing with thin dolls influences body image, the dolls directly affected actual food intake in these young girls.
\end{abstract}

Keywords Barbie doll · Emme doll · Thin dolls .

Body image $\cdot$ Food intake $\cdot$ Young girls

\section{Introduction}

The present study experimentally tested the direct effects of exposure to thin dolls on body image and food intake in a sample of young Dutch girls. An increasing number of studies have demonstrated the link between thin ideal exposure and body image in young Australian children (e.g., Ricciardelli and McCabe 2001). For example, watching television and perceiving pressure to be thin from the media were found to be related to increased awareness of weight loss strategies and disturbed eating behavior over time in young North American and Australian children

D. J. Anschutz $(\bowtie) \cdot$ R. C. M. E. Engels

Behavioural Science Institute, Radboud University, P.O. Box 9104, 6500 HE Nijmegen, The Netherlands e-mail: d.anschutz@pwo.ru.nl
(Harrison and Hefner 2006; McCabe and Ricciardelli 2005). As girls in Western societies (like The Netherlands) are frequently exposed to thin fashion dolls, this might affect the development of their body image and eating behaviors as well. Since little is known about the effects of playing with thin dolls, it is important to investigate the effects of doing so on young girls' body image and eating behavior.

Numerous studies have shown that children in Western societies experience body image concerns at a very young age (Davison et al. 2003; Hill et al. 1994; Hill and Robinson 1991; Schur et al. 2000; Shunk and Birch 2004). This research stresses the significance of studying socio-cultural influences on children (e.g., Clark and Tiggemann 2006; Collins 1991). Children learn through observing and imitating behaviors they see in their environment (Villani 2001). For example, in children's media, beauty is often associated with goodness, whereas ugliness is associated with badness (Herbozo et al. 2004). Furthermore, the media teaches children that obese children have fewer friends, are less liked by their parents, are lazier, and less happy than normal weight children (Hebl and Heatherton 1998; Hebl and Turchin 2005; Hill and Silver 1995). Young girls are found to be especially susceptible to thin ideal media, negatively affecting body satisfaction and promoting disturbed eating behaviors such as dieting (e.g., Moriarty and Harrison 2008; Phares et al. 2004). Many young girls indicate using media as an important source of information about dieting (Lawrie et al. 2007; Schur et al. 2000).

Like children's media, playing with toys is also part of the socialization process of children (Sutton-Smith 1985). Fashion dolls might serve as role models for young girls. Playing with these dolls might provide girls with mental representations of what is expected of them later in life, 
with respect to their social skills as well as their body appearance. The most famous fashion doll in the world is probably Mattel's Barbie. In Western societies, almost all girls own one or more Barbie dolls (Rogers 1999). Particularly famous aspects of Barbie are her body shape and proportions that have been criticized for being extremely unrealistic (e.g., Brownell and Napolitano 1995; Pedersen and Markee 1991). Norton et al. (1996) showed that the probability for such a body shape is less than 1 in 100,000 women. Since many young girls are exposed to this unrealistic thin ideal by playing with Barbie dolls, this might affect how they look at themselves.

Although there has been discussion about the extremely thin body of Barbie, only one experimental study actually tested the effects of exposure to images of Barbie on body image in a sample of young girls' from the United Kingdom (Dittmar et al. 2006). In that study, 5- to 8-yearold girls were exposed to images of Barbie or to images of Emme (developed by Tonner); a doll with more realistic body proportions that was endorsed by the American Dietetic Association as a healthy role model for young girls. They found that girls between the ages of 5.5 to 7.5 years old had lower body esteem scores and a greater discrepancy between actual and ideal body sizes or actual and adult body sizes (relative difference between the actual body size of the girl and her desired adult body size) if they were exposed to images of a Barbie, whereas exposure to images of the Emme doll had no effects on these variables. However, children between the ages of 7.5 and 8.5 experienced greater actual and adult body discrepancies if exposed to images of Emme, whereas no effects were found for exposure to images of Barbie in this age group. Dittmar et al. (2006) reasoned that the age difference they found can be explained by the fact that the girls under the age of 7.5 are still developing a self-concept and therefore use Barbie actively as a reference norm, whereas girls older than 7.5 years have already internalized the thin ideal as a cognitive self-concept structure (see also Vygotsky 1991).

In the present study, we aimed at replicating and extending the study by Dittmar et al. (2006) by testing the effects of actually playing with thin dolls vs. playing with an average sized doll. Dittmar et al. (2006) found lower body esteem and higher body dissatisfaction in girls after exposure to images of the Barbie doll as compared to images of the Emme doll and the control condition. No differences between the Emme doll and the control condition were found on these variables. Dittmar et al. (2006) used pictures of the dolls as stimulus material in their experiment. It is possible that actually playing with the doll would have more profound effects since the body proportions of the doll become even more salient when they actually handle it. In addition, because the Emme doll does differ from the Barbie doll not only in body size but also literally in height and weight (see Fig. 1), a larger but equally slim doll (Tyler) as Barbie was included in the present study to control for the possible confounding effect of the smaller size of the Barbie doll. In addition, following Dittmar et al. (2006), a neutral condition was included to serve as a baseline condition for girls' body image which involved playing with Legos instead of a doll. Similar to Dittmar et al. (2006), age differences were tested in the present study. Since we know that negative body image and dissatisfaction are associated with unhealthy eating behaviors such as dieting and bulimic eating behaviors (e.g., Stice 2001), it is essential to test whether playing with these different-sized dolls has a direct impact on eating behavior. Therefore, we included food intake as a dependent measure in the present study.

To summarize, girls were randomly assigned to play with a thin doll, average-sized doll, or no doll (Legos) for $10 \mathrm{~min}$, and then took part in a taste test as a measure of actual food intake. The following hypotheses were tested:

H1: We expect that girls who played with thin dolls would report lower body esteem compared to girls who played with the average-size doll or girls in the control condition, and that this effect would be moderated by age such that younger girls would report lower body esteem than older girls. We did not expect the average size doll condition to differ from the control condition on body esteem.

$\mathrm{H} 2$ : We expect that girls who played with thin dolls would report a larger actual-ideal body size discrepancy compared to girls who played with the average-size

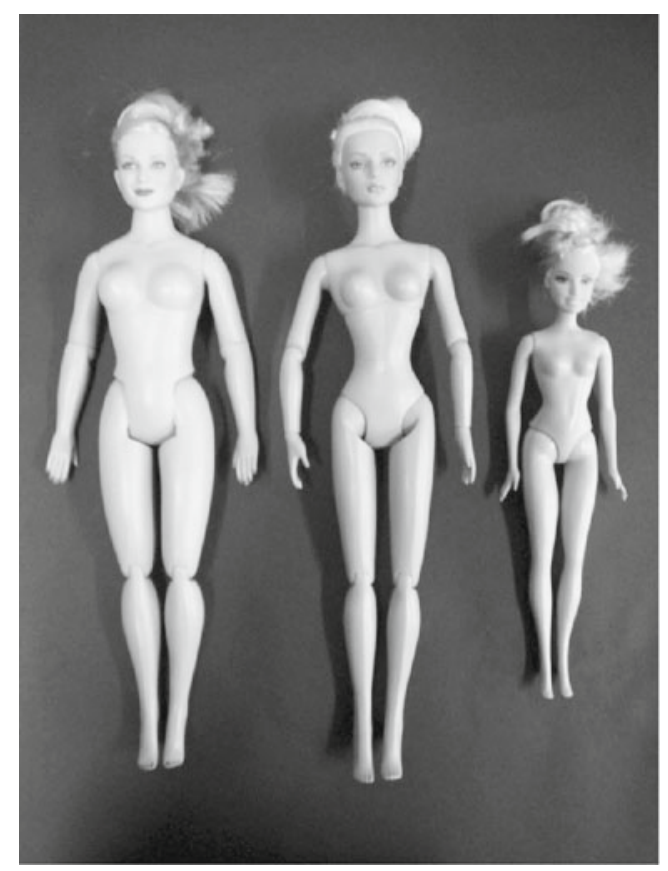

Fig. 1 Dolls (Emme, Tyler, and Barbie respectively) 
doll or girls in the control condition, and that this effect would be moderated by age such that younger girls would report a larger actual-ideal body size discrepancy than older girls. We did not expect the average size doll condition to differ from the control condition on actual-ideal body size discrepancy.

H3: We expect that girls who played with thin dolls would eat less food compared to girls who played with the average-size doll or girls in the control condition, and that this effect would be moderated by age such that younger girls would eat less food than older girls. We did not expect the average size doll condition to differ from the control condition on food intake.

\section{Method}

Participants

The sample consisted of 117 girls (grades 1 to 4) from seven primary schools in the southeast of The Netherlands. Most girls were native Dutch citizens $(N=111)$. Six girls were born in different countries (Belgium, China, Ireland, Indonesia, Syria and Thailand). Exclusion of these girls did not alter the results, so it was decided to include them in the analyses. The mean age of the sample was $8.04(\mathrm{SD}=1.32)$. Mean age across conditions did not significantly differ, $F(2,116)=1.81, p=.17$, cohen's $f=.18$ : thin dolls $(N=57$; $\mathrm{M}=8.07, \mathrm{SD}=1.35)$, average-sized dolls $(N=33 ; \mathrm{M}=7.73$, $\mathrm{SD}=1.13)$, and no doll $(N=27 ; \mathrm{M}=8.37, \mathrm{SD}=1.45)$. The mean body mass index (BMI) of the girls was $17.28(\mathrm{SD}=$ 2.70). Mean BMI across conditions did not differ significantly, $F(2,116)=.13, p=.88$, cohen's $f=.05$ : thin dolls $(N=57$; $\mathrm{M}=17.17, \mathrm{SD}=2.82)$, average-sized dolls $(N=33 ; \mathrm{M}=17.48$, $\mathrm{SD}=2.54)$, and no doll $(N=27 ; \mathrm{M}=17.25, \mathrm{SD}=2.72)$.

Materials and Measures

Dolls

In one condition the girls played with a Barbie (Mattel ${ }^{\circledR}$ ). In a second condition girls played with an Emme doll that was especially made with a realistic body size, based on the full-figured American fashion model Emme. Barbie's body represents a U.S. dress size 2, whereas Emme represents a U.S. dress size 16 (Dittmar et al. 2006). The problem with comparing the Barbie to the Emme doll is that the Emme doll is not only larger in body size, the doll itself is also taller than Barbie. To control for differences in the height of the dolls, we included a third condition with another doll also developed by Tonner (from Tonner's Tyler Wentworth Collection) that is comparable in height to Emme, but also very slim like Barbie, which we refer to as the Tyler doll. Figure 1 depicts images of the three dolls used in this study.

\section{Body Size of the Doll}

To check whether the girls actually noticed the different body sizes of the dolls, they were asked to indicate the body figure of the doll. We presented the girls with nine female body silhouette drawings ranging from very thin to very large (Stunkard et al. 1983) and asked the girls to indicate which picture looked most like the doll they just played with. Further, the girls were presented with a Visual Analogue Scale (VAS), which comprises a line of $140 \mathrm{~mm}$ on which they were asked to indicate to what extent they considered the doll they just played with as thin.

Dependent Variables

\section{Body Esteem}

To be able to compare our results with the results of Dittmar et al. (2006) we used the same measure to investigate body esteem. Their final scale consisted of 6 items measuring perceived appearance by others (e.g., 'Children my own age like my looks'), weight perception (e.g., 'My weight makes me happy') and non-specific body esteem (e.g., 'I am proud of my body'). Like Dittmar et al. (2006), we used a response format with pictures of smiley's in which the girls had three response options; 'no', 'in between', and 'yes'. They were scored with a ' 0 ', ' 1 ' or ' 2 ', respectively. Facial pictures were used to illustrate the response options. The items were summed and divided by 6 to create a body esteem score for each girl. All statements were positively worded, so a higher score on this measure indicates greater body esteem. Cronbach's alpha in our sample was .64.

\section{Actual-Ideal Body Size Discrepancy}

To measure the actual-ideal body size discrepancy the Children Figure Rating Scale was used (see Tiggemann and Wilson-Barrett 1996). A series of nine drawings of girls' body figures, ranging from very thin to very fat, were presented. The girls were asked to indicate which drawing looked most similar to their own current body shape, and which one would be their ideal body shape. The difference between the reported current body shape and the ideal body shape was used as a measure of body dissatisfaction. A positive score indicated a discrepancy between the current and the ideal body shape; this meant that the girl wanted to be thinner than she actually reported to be. Scoring a zero indicated that there was no difference between the current and the ideal body shape, which meant that the girl was 
satisfied with her body shape. A negative score indicated that the girl wanted to be larger than she actually reported to be. The use of the Figure Rating Scale has proven valid for use in young children (Gardner et al. 1997) and has good test-retest reliability (e.g., Veron-Guidry and Williamson 1996; Wood et al. 1996).

\section{Food Intake}

During the taste test the girls could freely eat from three bowls filled with chocolate-coated peanuts. The amount of test food the girls ate during the taste test was measured with a professional scale (Kern 440) and the total amount of test food eaten (in grams) represented their food intake.

Covariates

$B M I$

BMI (weight $(\mathrm{kg}) /$ height $^{2}(\mathrm{~m})$ ) was calculated based on measured height and weight. Weight was measured in light clothing and without shoes to the nearest $.1 \mathrm{~kg}$. Height was measured according to standard procedures (without shoes), to the nearest $.5 \mathrm{~cm}$.

\section{Satiety}

Food intake may depend on level of satiety. We aimed to control for individual differences in state of caloric deprivation, so we asked the girls to indicate on a VAS $(140 \mathrm{~mm})$ to what extent they felt hungry just before they participated in the experiment (ranging from 'not at all hungry!' to 'very hungry!'). To avoid demand characteristics we assessed the satiety level of the girls after the experimental manipulation (see also Anschutz et al. 2008; Anschutz et al. 2009).

\section{Liking of Testfood}

We controlled for liking of chocolate-coated peanuts by presenting the girls with a VAS $(140 \mathrm{~mm})$ to measure the extent to which they liked the test food (ranging from 'I totally do not like it' to 'I totally like it').

Moderating Variables (Additional Analyses)

\section{Owning a Barbie}

We investigated whether the girls in our sample owned a Barbie at home by asking them the question whether they owned a Barbie or not. They could indicate whether 'yes' or 'no' they owned a Barbie (or more than one) at home.

\section{Time Spent Playing with Barbie}

To get an approximate indication of how much time the girls normally spent playing with Barbie, we asked them the following question: 'How often do you play with Barbie?' Response options were 'never' 'sometimes' or 'every day' (values '0', '1', and '2' respectively).

\section{Enjoyment of the Experiment}

We investigated the level of enjoyment of participating in the experiment by presenting the girls with a VAS $(140 \mathrm{~mm})$ to measure the extent to which they liked playing in the experimental session (ranging from 'I did not like it at all!' to 'I liked it very much!').

\section{Procedure}

We obtained approval for the current study from the ethical committee of the faculty of social sciences, Radboud University. After gaining consent from the schools to participate, the parents of the children received a letter in which they were fully informed about the purpose of the study and were asked whether they would allow their child to participate or not (active informed consent). Girls who were allergic to the test food (i.e., chocolate coated peanuts) were excluded from participation.

All girls were tested in a separate room at their schools during regular school hours for approximately $30 \mathrm{~min}$ per session. There were four conditions within a randomized experimental design: Barbie doll, Emme doll, Tyler doll, and Control. During the first $10 \mathrm{~min}$ of the session, the girls played with the dolls or LEGO ${ }^{\circledR}$. When playing with one of the dolls, the girls were instructed to dress the doll for a party and a working day. They started by playing with a naked doll to make sure they had seen the body of the doll. The setting in which they played was a dressing room for dolls, with all kinds of dolls clothes and accessories the girls could use. Girls in the control condition were asked to build a house with the $\mathrm{LEGO}^{\circledR}$. The experimenter was sitting next to the girls and tried to make the girls feel comfortable if needed, but did not interfere with the play. After approximately $10 \mathrm{~min}$ of playing, the girls filled out questionnaires concerning their body esteem and body shape satisfaction. Then, the experimenter presented the girls with three pre-weighed bowls of chocolate-coated peanuts with one colour in each bowl. The girls were told that they had to evaluate the chocolate-coated peanuts in order to decide which colour tasted best. They were told that 
the experimenter would leave them alone for several minutes and they could eat whatever they liked from the test food to determine which colour tasted best. Then the experimenter left the room and returned after $8 \mathrm{~min}$. Subsequently, girls had to fill out the other questionnaires of interest. These questionnaires comprised measures of our dependent variables (body esteem and actual-ideal body size discrepancy), manipulation check (body size of the dolls), possible covariates (satiety, liking of the test food), and moderating variables (owning a Barbie, time spent playing with Barbie, enjoyment of the experiment). Finally, to calculate BMI, their height and weight was measured. All girls were asked not to talk about the experiment with their classmates. After data collection and analyses were finished, all participating schools were informed about the results of the study.

\section{Preliminary Analyses}

A MANCOVA was conducted to check whether there were any differences between the effects of exposure to the two thin dolls (Barbie vs. Tyler) on body esteem, actualideal body size discrepancy or food intake (controlling for BMI). Results of this MANCOVA revealed no significant difference between the two conditions on body esteem, $F(1,52)=.33, p=.57$, cohen's $f=.08$, actual-ideal body size discrepancy, $F(1,52)=.90, p=.35$, cohen's $f=.13$, or food intake, $F(1,52)=1.19, p=.28$, cohen's $f=.15$. In addition, no significant interactions between condition and age group were found for body esteem, $F(1,52)=.04, p=.85$, cohen's $f=.03$, actual-ideal discrepancy, $F(1,52)=.80, p=.38$, cohen's $f=.12$, or food intake, $F(1,52)=.63, p=.43$, cohen's $f=.11$. Since the Barbie and Tyler conditions are conceptually equal (both conditions constitute thin doll exposure) and no specific differences were expected between these conditions, it was decided to combine both conditions into one thin doll exposure condition for the main analyses because no differences are found.

In the "Results" section, a series of ANCOVAs are presented that tested main and interaction effects of condition and age on body esteem, actual-ideal body discrepancy, and food intake. Following Dittmar et al. (2006), age was categorized into two groups; girls under 7.5 years of age $(N=42)$ and girls over 7.5 years of age $(N=75)$. BMI was included as a covariate in all analyses, because BMI and body dissatisfaction (e.g., Yates et al. 2004) as well as BMI and food intake (e.g., MacDiarmid et al. 1998) have been found to be related. Satiety $(r=.10$, $p=.28)$ and liking of the test food $(r=.15, p=.12)$ were not significantly associated with food intake, and were therefore not included as covariates in the analyses regarding food intake. First, manipulation checks were conducted to examine the perceived body size of the dolls. Further, three
3 (condition; thin dolls, average size doll, no-doll control) $\times$ 2 (age group; under and over 7.5) ANCOVA's were conducted to test the effects on body esteem, actual-ideal body size discrepancy and food intake of the girls ( $\mathrm{H} 1, \mathrm{H} 2$, and $\mathrm{H} 3$ ), controlling for BMI.

Cohen's $d$ was reported to indicate the effect size of the main effects of age group. We used Cohen's $f$ instead of Cohen's $d$ to indicate the effect size of the main effects of condition, since we had more than two conditions in our design (see Cohen 1988). To indicate effect sizes of comparisons between two conditions, we used Hedges $g$ instead of Cohen's $d$, since we had unequal numbers of participants and unequal variances over conditions (Hedges and Olkin 1985). Cohen's $d$ 's of $.20, .50$, and .80 represent small, medium and large effect sizes, respectively. Effect sizes (Cohen's $f$ and Hedges $g$ ) of .10, .25, and .40 are considered small, medium and large, respectively.

\section{Results}

\section{Manipulation Check}

There were significant differences found between the girl's perceptions of the doll's body size between conditions on both the body figure rating of the doll, $\mathrm{F}(2,89)=53.21$, $p<.001$, and the VAS slimness, $\mathrm{F}(2,89)=18.30, p<.001$, with large effect sizes (Cohen's $f$ ) of 1.08 and .62 respectively. Post-hoc comparisons with Bonferroni corrections for multiple testing revealed that our manipulation was successful as the girls rated Barbie as being significantly slimmer than the average sized Emme doll on both the figure rating scale $(p<.001$; Hedges $g>2)$ and the VAS slimness $(p<.001$; Hedges $g=1.7)$. The slim Tyler doll was rated to be significantly slimmer than the Emme doll on both the figure rating scale $(p<.001$; Hedges $g>2)$, and the VAS slimness $(p=.001$; Hedges $g$ of .6). No significant differences were found between Barbie and the Tyler doll on both the figure rating scale and the VAS slimness, which indicates that the conditions could be combined into a single thin doll condition for analysis.

\section{Descriptives}

Table 1 shows the means and SDs of all variables, split by condition. Liking of the test food was in general quite high. A MANOVA revealed no significant differences between conditions on satiety, $F(3,112)=2.09, p=.11$, cohen's $f=.24$, liking of test food, $F(3,112)=2.46, p=.07$, cohen's $f=.26$, age, $F(3,112)=1.27, p=.29$, cohen's $f=.18$ or BMI, $F(3,112)=.49, p=.69$, cohen's $f=.11$, indicating that randomization was successful. 
Table 1 Means (Standard Deviations) of all variables separated by condition

\begin{tabular}{|c|c|c|c|c|}
\hline Measures & Barbie doll $(N=29)$ & Emme doll $(N=33)$ & Tyler doll $(N=28)$ & $\operatorname{LEGO}^{\circledR}(N=27)$ \\
\hline \multicolumn{5}{|l|}{ Manipulation check } \\
\hline Ratings of doll size $\mathrm{e}^{\mathrm{a}}$ & $2.57(.78)$ & $5.06(1.27)$ & $2.99(.92)$ & - \\
\hline Slimness doll (VAS) ${ }^{\mathrm{b}}$ & $2.82(1.48)$ & $6.01(2.79)$ & $3.91(1.73)$ & - \\
\hline \multicolumn{5}{|l|}{ Covariates } \\
\hline Satiety $\left(\right.$ VAS) ${ }^{\mathrm{b}}$ & $4.14(3.58)$ & $6.07(3.81)$ & $6.91(2.95)$ & $4.77(3.78)$ \\
\hline Liking of test food (VAS) & $11.48(2.02)$ & $11.54(2.40)$ & $10.19(2.64)$ & $11.67(2.12)$ \\
\hline \multicolumn{5}{|l|}{ Moderator variable } \\
\hline Age & $7.97(1.27)$ & $7.73(1.13)$ & $8.18(1.44)$ & $8.37(1.45)$ \\
\hline Owning a Barbie (yes/no) & $26 / 3$ & $27 / 6$ & $25 / 3$ & $25 / 2$ \\
\hline Time spent playing with Barbie ${ }^{c}$ & $.97(.63)$ & $.94(.56)$ & $.82(.48)$ & $.93(.62)$ \\
\hline Enjoyment of experiment (VAS) ${ }^{b}$ & $9.32(4.00)$ & $10.80(3.64)$ & $10.98(3.08)$ & $10.70(2.75)$ \\
\hline \multicolumn{5}{|l|}{ Dependent variables } \\
\hline Body esteem ${ }^{\mathrm{d}}$ & $1.55(.32)$ & $1.53(.38)$ & $1.63(.29)$ & $1.57(.32)$ \\
\hline Body size discrepancy $^{\mathrm{e}}$ & $.69(1.37)$ & $.88(1.22)$ & $.32(1.31)$ & $.48(1.09)$ \\
\hline Food intake (gram) & $30.81(21.75)$ & $45.04(25.84)$ & $35.79(18.88)$ & $32.02(16.30)$ \\
\hline
\end{tabular}

${ }^{\mathrm{a}}$ This scale ranged from 1 to 9 (nine body silhouettes were presented)

${ }^{\mathrm{b}}$ All VAS lines were $140 \mathrm{~mm}$, so scores (in $\mathrm{cm}$ ) could range from .00 to 14.00

${ }^{\mathrm{c}}$ Scores on this scale could range from 0 to 2

${ }^{\mathrm{d}}$ Scores on this scale could range from 0 to 2

${ }^{\mathrm{e}}$ Body size discrepancy represented the difference between actual and ideal body figures of the girls, which both ranged between 1 and 9 (nine body silhouettes were presented)

Table 2 shows the correlations between all variables. A significant negative correlation was found among age and body size discrepancy, with older girls experiencing less body size discrepancy. Further, a higher BMI was significantly related to a larger body size discrepancy and lower body esteem. Remarkably, no significant relation was found between food intake and body esteem or body size discrepancy.

\section{Body Esteem}

A 3 (Thin vs. Average vs. Control) $\times 2$ (Younger vs. Older) ANCOVA, controlling for BMI, was conducted to test H1. A significant effect was found for BMI, $F(1,110)=14.86$, $p=.001$. This covariate effect indicates that a higher BMI

Table 2 Correlations among the main variables $(N=117)$

\begin{tabular}{lllll}
\hline Measures & Age & BMI & $\begin{array}{l}\text { Body size } \\
\text { discrepancy }\end{array}$ & $\begin{array}{l}\text { Body } \\
\text { esteem }\end{array}$ \\
\hline Age & - & & & \\
BMI & .03 & - & & \\
Body size discrepancy & $-.23^{*}$ & $.24 * *$ & - & - \\
Body esteem & -.15 & $-.34^{* *}$ & -.06 & .03 \\
Food intake & .05 & .06 & .03 & \\
\hline
\end{tabular}

${ }^{*} p<.05, * * p<.01, * * * p<.001$ was related to lower body esteem. No main effect of exposure condition was found, $F(2,110)=.34, p=.71$, cohen's $f=.08$, indicating that the body esteem of the girls did not differ between the three conditions. In addition, no main effect was found for age group, $F(2,110)=2.35$, $p=.13$, cohen's $d=.32$, indicating that body esteem did not differ between girls in the younger and older age group. The interaction between condition and age group on body esteem was also not significant, $F(2,110)=.11, p=.89$, cohen's $f=.04$. So, H1 was not supported, as playing with thin dolls vs. average size or no dolls did not significantly alter body esteem, and age did not moderate this pattern of effects.

\section{Actual-Ideal Body Size Discrepancy}

In general, $15.4 \%$ of the girls wanted a larger body size, $35.9 \%$ were satisfied with their body size, and as many as 48.7\% wanted a thinner body size.

A second 3 (Thin vs. Average vs. Control) $\times 2$ (Younger vs. Older) ANCOVA, controlling for BMI, was conducted to test $\mathrm{H} 2$. The covariate effect of BMI on actual-ideal body size discrepancy was significant, $F(1,110)=6.32, p=.01$. A higher BMI was related to greater actual-ideal body size discrepancy. No main effect was found for condition, $F(2,110)=.54, p=.58$, cohen's $f=.10$, indicating that the actual-ideal body size discrepancy of the girls did not differ 
between the thin dolls, average size doll and control condition. A significant main effects of age group, $F(1,110)=8.52$, $p=.02$, cohen's $d=.82$ was found on actual-ideal body size discrepancy. Girls under the age of 7.5 experienced a greater actual-ideal body size discrepancy compared to girls over the age of 7.5. No significant interaction between condition and age group, $F(2,110)=.09, p=.92$, cohen's $f=.04$, was found on actual-ideal body size discrepancy. In sum, $\mathrm{H} 2$ was not supported, as playing with thin dolls vs. average size or no dolls did not significantly alter actual-ideal body size discrepancy. In addition, age did not moderate the relation between doll exposure and actual-ideal body size discrepancy.

\section{Food Intake}

A final 3 (Thin vs. Average vs. Control) $\times 2$ (Younger vs. Older) ANCOVA with food intake as a dependent measure, controlling for BMI, was conducted to test H3. No significant covariate effect was found of BMI on food intake, $F(1,110)=.45, p=.50$. This indicates that food intake was not related to BMI level. The results showed that condition had a significant main effect on food intake, $F(2,110)=$ 3.93, $p=.02$; Cohen's $f=.27$. Post-hoc comparisons with Bonferroni corrections for multiple testing revealed that the girls in the average size doll condition ate significantly more than the girls in the thin doll condition $(p=.03$; Hedges $g>1.0$ ). No significant difference in food intake was found between the average size doll condition and the no-doll control condition $(p=.12$; Hedges $g=.70)$, or between the thin doll condition and the no-doll control condition ( $p=1.00$; Hedges $g=.04$ ). Further, age group had no main effect on food intake, $F(1,110)=.24, p=.63$, cohen's $d=.09$. So, food intake in the present experiment did not differ between the younger and older girls. The interaction between condition and age was not significant, $F(2,110)=.42, p=.66$, cohen's $f=.08$. Figure 2 shows the adjusted means of food intake (in grams) in all three conditions (10 grams of the M\&M's eaten equals $48.4 \mathrm{kcal}$

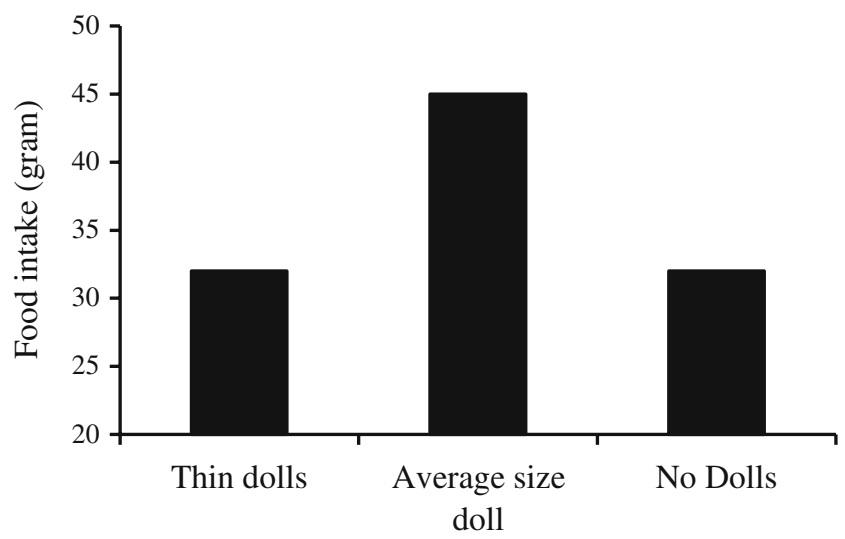

Fig. 2 Adjusted means of food intake (in gram) in all three conditions intake). In the thin doll condition the girls ate on average 32.2 grams $(\mathrm{SE}=3.0)$, in the average sized doll condition they ate on average 45.0 grams $(\mathrm{SE}=3.8)$ and in the control condition they ate on average 32.4 grams $(\mathrm{SE}=4.7)$. In conclusion, $\mathrm{H} 3$ was partly supported, as girls ate less after exposure to the thin dolls than after exposure to the average sized doll. However, this effect was not moderated by age.

\section{Additional Analyses}

To check for some alternative moderators in the relation between condition and body image and food intake some additional MANOVA's were conducted to test for interactions between condition and the particular moderator. First, we wanted to check whether owning a Barbie or not influenced our results. Only 14 of the 117 girls reported that they did not own at least one Barbie. No significant interaction effects between condition and owning a Barbie were found for body esteem, $F(2,111)=.81 p=.45$, cohen's $f=.12$, actual-ideal body size discrepancy, $F(2,111)=.07$, $p=.94$, cohen's $f=.03$, or food intake, $F(2,111)=.30$, $p=.74$, cohen's $f=.07$. Second, the amount of time girls normally spent playing with dolls might moderate the effects of the exposure condition. However, no significant interaction effects between condition and time spent playing with Barbie were found for body esteem, $F(4,108)=$ $1.00, p=.41$, cohen's $f=.19$, actual-ideal body size discrepancy, $F(4,108)=.71, p=.59$, cohen's $f=.16$, or food intake, $F(4,108)=2.08, p=.09$, cohen's $f=.28$. Third, how much the girls enjoyed playing in the experiment could moderate the extent to which they were affected by the dolls. However, no significant interaction effects between condition and girls' reports of how much they liked playing in the experiment were found for body esteem, $F(2,111)=.91$, $p=.40$, cohen's $f=.13$, actual-ideal body size discrepancy, $F(2,111)=.07, p=.93$, cohen's $f=.03$, or food intake, $F(2,111)=.60, p=.55$, cohen's $f=.11$.

\section{Discussion}

In the present study we compared the effects of playing with a thin doll to playing with an average sized doll or no doll on body image and actual food intake in young girls. The most important finding was that girls who played with the average sized doll ate significantly more than girls who played with a thin doll.

Contrary to Dittmar et al. (2006), we did not find that exposure to a thin doll negatively affected body esteem or actual-ideal body size discrepancy compared with exposure to an average-sized doll for girls younger or older than 7.5 years. An explanation might be that Dittmar et al. (2006) exposed the girls to a picture book with images of 
the dolls - which might not be different from exposure to thin models in magazines- whereas the girls in our study actually played with the dolls. Magazine exposure might indirectly imply more 'aggressive' norm-setting, since it is a form of media exposure and the media is known for setting social and cultural norms regarding appearance even in young children (Lawrie et al. 2007). In Dittmar et al. (2006), the images of the dolls might actually have functioned as thin model images. We know from the literature that exposure to slim model images is related to higher body dissatisfaction than exposure to average or oversized model images (for reviews see Grabe et al. 2008; Groesz et al. 2002). It is important to keep in mind that the young girls in the current study were aware of the body size of the dolls, as is shown by the substantial differences between experimental conditions on the manipulation check. Thus, the lack of effects on girls' body image cannot be explained by the fact that they did not notice the dolls' body sizes. Still, when exposed to a real doll the girls might experience less external pressure, because they are in control of the play and no explicit norms are imposed by the environment. Therefore this type of exposure might not directly affect their body image, which might be rather stable. Future studies might explicitly compare the effects of toys with the effects of portrayals of thin images in the media.

Interestingly, we did find an effect on girls' actual eating behavior. They ate less food when they played with the thin dolls than when they played with the average sized doll. Perhaps the girls were inspired by the Barbie to achieve a slim body and therefore ate less. Results of previous studies showed that young girls are already aware of the thin ideal and weight loss strategies to achieve this ideal (e.g., Dohnt and Tiggemann 2004). However, closer inspection of the means indicated that the girls ate more when they played with the average sized Emme doll instead of eating less when they played with the thin dolls. This might be explained by the fact that exposure to a heavier model leads to elevated food intake. In a different context, studies focusing on imitation of eating behavior revealed that the physical appearance of a model can influence the 'normative' standard of food intake in an eating context (Salvy et al. 2007). Hermans et al. (2008) found that the Dutch female students in their experiment only imitated the elevated intake of a confederate if the confederate was of normal weight, and not if the confederate was slim. Although the dolls in our study did not eat, it still might have been the case that their physical appearance created a differential eating context in which the average sized doll created a context where eating an unrestricted amount of test food would be normative and socially accepted. Accordingly, the body size of a model in a certain context might refer to a normative eating standard (Anschutz et al. 2008), which might explain why the girls in the present study ate more when they played with the average sized doll. Different types of norms might apply to food intake compared to body image, as body image was not affected in the present study. Norms regarding body image might be related to 'thinness' (so these norms might be communicated by thin images/dolls), whereas our results regarding food intake suggest that it was actually the larger doll that carried out a norm regarding food intake.

The average-sized doll might also have caused a relief effect. This relief effect, implying that some women feel better about their own body and might even eat more after exposure to average sized media models, was previously found in adult females (Anschutz et al. 2008; Dittmar and Howard 2004). In the current study, playing with a more realistically proportioned doll may have freed the girls from dietary restraint and made them feel that they could take as many sweets as they wanted. This explanation is further supported by the finding that almost half of the girls in our sample desired a thinner body size. It would be interesting to replicate the present study using healthy test food. It could be examined whether the girls would also eat more healthy food after exposure to an average sized doll, which would then clearly be a positive eating behavior. Another suggestion for future research might be to let the girls play that they are preparing a dinner, using a setting with all kinds of foods (healthy and unhealthy), to see whether they are more likely to choose healthy foods and maybe also less food when they play with a thin doll than when playing with an average sized doll.

A remarkable finding of the present study was that no significant correlation was found between food intake and body esteem or body size discrepancy, as was previously found in adults (e.g., Stice 2001). Perhaps the female children in our study have not yet fully developed a coherent self-concept (Marsh et al. 1998), including body image as a cognitive construct. This implies that although young children display behaviors related to appearance enhancement in relation to thin ideal cues, they do not express dissatisfaction with their body in accordance yet (see also Hayes and Tantleff-Dunn 2010). However, this assumption remains speculative and requires further examination in future research.

\section{Limitations and Future Directions}

It should be mentioned that we do not know what the longterm effects of playing with a doll could be on body image and food intake in young girls. A suggestion for future study would be to investigate the long-term effects of playing with a thin doll, and to compare these with the effects of playing with a more average sized doll like Emme, starting with the first time the girls are exposed to the dolls. Young girls who have never been exposed before 
to a Barbie or Tonner doll could participate in the study, in which the girls would be exposed to a Barbie or Tonner doll at certain (controlled) time points. Right after the exposure, body image and actual food intake could be measured. This design could provide more insight into the effects of doll exposure over time. Another suggestion would be to focus on young boys by examining the effects of exposure to action hero toys with different body sizes on body image and appearance-related behaviors in boys. Pope et al. (1999) showed that male action toys have grown much more muscular over time and became highly unrealistic. Additionally, previous studies also showed that exposure to the male beauty ideal is related to body image concerns in men (e.g., Jones and Crawford 2005; Olivardia et al. 2004). Moreover, previous research in adult men showed that handling unrealistic proportioned action figures was related to a decrease in body esteem (Barlett et al. 2005). The present sample was slightly older than the sample used by Dittmar et al. (2006). Since the older children reported still playing with dolls, we did not consider our sample too old for comparison with the Dittmar et al. study. However, in future studies we will aim at testing the effects of playing with dolls in a younger sample.

Future studies could also use a different measure of body esteem to investigate how consistent the present findings with regard to body esteem are. At least in our Dutch sample, we noted that the reliability of the scale was rather low, which is a limitation of the present study's investigation of the effects of our manipulation on this dependent variable. The body esteem scale of Dittmar et al. (2006) assesses different aspects of body esteem (e.g., weight related body esteem or concerns regarding own appearance as perceived by others) with only six items in total, which might have made the construct that was measured less cohesive. Further, low alpha's were found in other studies using self-report questionnaires when assessing psychological constructs in young children (e.g., Putnam and Rothbart 2006; Rothbart et al. 2001). A suggestion for future research might be to use the Body-Esteem Scale (Mendelson et al. 1996). This scale was designed to assess children's attitudes and feelings about their bodily appearance and was found to have good internal consistency in a young children's sample (see also Ricciardelli and McCabe 2001).

In sum, the present study is the first to compare the effects of actually playing with different-sized dolls on body image and food intake among young girls. Body image did not differ for girls who played with thin dolls vs. average-sized dolls; but the girls who played with averagesized dolls ate more than the girls who played with thin dolls. Since girls in Western societies are frequently exposed to fashion dolls, it is important to further examine the effects of exposure to these dolls on their body image and eating behaviors.
Open Access This article is distributed under the terms of the Creative Commons Attribution Noncommercial License which permits any noncommercial use, distribution, and reproduction in any medium, provided the original author(s) and source are credited.

\section{References}

Anschutz, D. J., Van Strien, T., Becker, E. S., \& Engels, R. C. M. E. (2008). The bold and the beautiful: The influence of body size of televised media models on body dissatisfaction and actual food intake. Appetite, 51, 530-537. doi:10.1016/j.appet.2008.04.004.

Anschutz, D. J., Engels, R. C. M. E., \& Van Strien, T. (2009). Side effects of television food commercials on concurrent nonadvertised sweet snack food intakes in young children. The American Journal of Clinical Nutrition, 89, 1328-1333. doi:10.3945/ajen. 2008.27075.

Barlett, C., Harris, R., Smith, S., \& Bonds-Raacke, J. (2005). Action figures and men. Sex Roles, 53, 11-12. doi:10.1007/s11199-0058304-4.

Brownell, K. D., \& Napolitano, M. A. (1995). Distorting reality for children: Body size proportions of Barbie and Ken dolls. The International Journal of Eating Disorders, 18, 295-298.

Clark, L., \& Tiggemann, M. (2006). Appearance culture in nine to 12-year old girls: Media and peer influences on body dissatisfaction. Social Development, 15, 628-643. doi:10.1111/j.14679507.2006.00361.

Cohen, J. (1988). Statistical power analysis for the behavioral sciences (2nd ed.). Hillsdale: Lawrence Erlbaum.

Collins, B. E. (1991). Body figure perceptions and preferences among preadolescent children. The International Journal of Eating Disorders, 10, 199-208.

Davison, K. K., Markey, C. N., \& Birch, L. L. (2003). A longitudinal examination of patterns in girls' weight concerns and body dissatisfaction from ages 5 to 9 years. The International Journal of Eating Disorders, 33, 320-332. doi:10.1002/eat.10142.

Dittmar, H., \& Howard, S. (2004). Professional hazards? The impact of models' body size on advertising effectiveness and women's body-focused anxiety in professions that do and do not emphasize the cultural ideal of thinness. The British Journal of Social Psychology, 43, 477-497. doi:10. 1348/0144666042565407.

Dittmar, H., Halliwell, E., \& Ive, S. (2006). Does Barbie make girls want to be thin? The effect of experimental exposure to images of dolls on the body image of 5- to 8-year-old girls. Developmental Psychology, 42, 283-292. doi:10.1037/0012-1649.42.2.283.

Dohnt, H. K., \& Tiggemann, M. (2004). Development of perceived body size and dieting awareness in young girls. Perceptual and Motor Skills, 99, 790-792. doi:10.1037/0012-1649.42.5.929.

Gardner, R. M., Sorter, R. G., \& Friedman, B. N. (1997). Developmental changes in children's body images. Journal of Social Behavior and Personality, 12, 1019-1036.

Grabe, S., Ward, L. M., \& Hyde, J. S. (2008). The role of the media in body image concerns among women: A meta-analysis of experimental and correlational studies. Psychological Bulletin, 134, 460-476. doi:10.1037/0033-2909.134.3.460.

Groesz, L. M., Levine, M. P., \& Murnen, S. K. (2002). The effects of experimental presentation of thin media images on body dissatisfaction: A meta-analytic review. The International Journal of Eating Disorders, 31, 1-16. doi:10.1002/eat.10005.

Harrison, K., \& Hefner, V. (2006). Media exposure, current and future body ideals, and disordered eating among preadolescent girls: A longitudinal panel study. Journal of Youth and Adolescence, 35, 153-163. doi:10.1007/s10964-005-9008-3. 
Hayes, S., \& Tantleff-Dunn, S. (2010). Am I too fat to be a princess? Examining the effects of popular children's media on young girls' body image? British Journal of Developmental Psychology, 28, 412-426. doi:10.1348/026151009X424240.

Hebl, M. R., \& Heatherton, T. F. (1998). The stigma of obesity in women: The difference is black and white. Personality and Social Psychology Bulletin, 24, 417-426.

Hebl, M. R., \& Turchin, J. M. (2005). The stigma of obesity: What about men? Basic and Applied Social Psychology, 27, 267-275. doi:10.1207/s15324834basp2703 8 .

Hedges, L. V., \& Olkin, I. (1985). Statistical methods for metaanalysis. San Diego: Academic.

Herbozo, S., Tantleff-Dunn, S., Gokee-Larose, J., \& Thompson, J. K. (2004). Beauty and thinness messages in children's media: A content analysis. Eating Disorders, 12, 21-34. doi:10.1080/ 10640260490267742.

Hermans, R. C., Larsen, J. K., Herman, C. P., \& Engels, R. C. (2008). Modeling of palatable food intake in female young adults: Effects of perceived body size. Appetite, 51, 512-518. doi:10.1016/j. appet.2008.03.016.

Hill, A. J., \& Robinson, A. (1991). Dieting concerns have a functional effect on the behaviour of nine-year-old girls. The British Journal of Clinical Psychology, 30, 265-267.

Hill, A. J., \& Silver, E. K. (1995). Fat, friendless and unhealthy: 9-year old children's perception of body shape stereotypes. International Journal of Obesity and Related Metabolic Disorders, $19,423-430$.

Hill, A. J., Draper, E., \& Stack, J. (1994). A weight on children's minds: Body shape and dissatisfaction at 9-years old. International Journal of Obesity and Related Metabolic Disorders, 18, 383-389.

Jones, D. C., \& Crawford, J. K. (2005). Adolescent boys and body image: Weight and muscularity concerns as dual pathways to body dissatisfaction. Journal of Youth and Adolescence, 34, 629636. doi:10.1007/s10964-005-8951-3.

Lawrie, Z., Sullivan, E. A., Davies, P. S., \& Hill, R. J. (2007). Body change strategies in children: Relationship to age and gender. Eating Disorders, 8, 357-363. doi:10.1016/j.eatbeh.2006.11.011.

MacDiarmid, J. I., Vail, A., Cade, J. E., \& Blundell, J. E. (1998). The sugar-fat relationship revisited: Differences in consumption between men and women of varying BMI. International Journal of Obesity, 22, 1053-1061.

Marsh, H. W., Craven, R. G., \& Debus, R. L. (1998). Structure, stability and development of young children's self-concepts: A multi-cohort-multi-occasion study. Child Development, 69, $1030-1053$

McCabe, M. P., \& Ricciardelli, L. A. (2005). A prospective study of pressures from parents, peers, and the media on extreme weight change behaviors among adolescent boys and girls. Behaviour Research and Therapy, 43, 653-668. doi:10.1016/j.brat.2004. 05.004 .

Mendelson, B. K., White, D. R., \& Mendelson, M. J. (1996). Selfesteem and body esteem: Effects of gender, age, and weight. Journal of Applied Developmental Psychology, 17, 321-346.

Moriarty, C. M., \& Harrison, K. (2008). Television exposure and disordered eating among children: A longitudinal panel study. The Journal of Communication, 58, 361-381. doi:10.1111/ j.1460-2466.2008.00389.x.

Norton, K. I., Olds, T. S., Olive, S., \& Dank, S. (1996). Ken and Barbie at life size. Sex Roles, 34, 287-294.

Olivardia, R., Pope, H. G., Jr., Borowiecki, J. J., \& Cohane, G. H. (2004). Biceps and body image: The relationship between muscularity and self-esteem, depression, and eating disorder symptoms. Psychology of Men and Masculinity, 5, 112-120. doi:10.1037/1524-9220.5.2.112.

Pedersen, E. L., \& Markee, N. L. (1991). Fashion dolls: Representations of ideals of beauty. Perceptual and Motor Skills, 73, 93-94.

Phares, V., Steinberg, A. R., \& Thompson, J. K. (2004). Gender differences in peer and parental influences: Body image disturbance, self-worth, and psychological functioning in preadolescent children. Journal of Youth and Adolescence, 33, 421429. doi:10.1023/B:JOYO.0000037634.18749.20.

Pope, H. G., Jr., Olivardia, R., Gruber, A., \& Borowiecki, J. (1999). Evolving ideals of male body image as seen through action toys. The International Journal of Eating Disorders, 26, 65-72.

Putnam, S. P., \& Rothbart, M. K. (2006). Development of Short and Very Short Forms of the Children's Behavior Questionnaire. Journal of Personality Assessment, 87, 103-113. doi:10.1207/ s15327752jpa8701 09.

Ricciardelli, L. A., \& McCabe, M. P. (2001). Children's body image concerns and eating disturbance: A review of the literature. Clinical Psychology Review, 21, 325-344. doi:8080/10.1016/ S0272-7358(99)00051-3.

Rogers, A. (1999). Barbie culture. Thousand oaks: Sage.

Rothbart, M. K., Ahadi, S. A., Hershey, K. L., \& Fisher, P. (2001). Investigations of temperament at three to seven years: The Children's Behavior Questionnaire. Child Development, 72, 1394-1408. doi:10.1111/1467-8624.00355.

Salvy, S. J., Romero, N., Paluch, R., \& Epstein, L. H. (2007). Peer influence on pre-adolescent girls' snack intake: Effects of weight status. Appetite, 49, 177-182. doi:10.1016/j.appet.2007.01.011.

Schur, E. A., Sanders, M., \& Steiner, H. (2000). Body dissatisfaction and dieting in young children. The International Journal of Eating Disorders, 27, 74-82.

Shunk, J. A., \& Birch, L. L. (2004). Validity of dietary restraint among 5- to 9-year old girls. Appetite, 42, 241-247. doi:10.1016/j. appet.2003.11.007.

Stice, E. (2001). A prospective test of the dual-pathway model of bulimic pathology: Mediating effects of dieting and negative affect. Journal of Abnormal Psychology, 110, 124-135. doi:10.1037//0021-843X.110.1.124.

Stunkard, A. J., Sorensen, T., \& Schulsinger, F. (1983). Use of the Danish Adoption Register for the study of obesity and thinness. Research Publications-Association for Research in Nervous and Mental Disease, 60, 115-120.

Sutton-Smith, B. (1985). Children's fiction making. Westport: Praeger/ Greenwood.

Tiggemann, M., \& Wilson-Barrett, E. (1996). Children's figure ratings: Relationship to self-esteem and negative stereotyping. The International Journal of Eating Disorders, 23, 83-88.

Veron-Guidry, S., \& Williamson, D. A. (1996). Development of a body image assessment procedure for children and preadolescents. The International Journal of Eating Disorders, 20, 287-293.

Villani, S. (2001). Impact of media on children and adolescents: A 10-year review of the research. Journal of the American Academy of Child and Adolescent Psychiatry, 40, 392-401.

Vygotsky, L. S. (1991). Genesis of higher mental functions. In P. Light, S. Sheldon, \& M. Woodhead (Eds.), Child development in social context (pp. 32-41). Florence: Taylor \& Francis/Routledge.

Wood, K. C., Becker, J. A., \& Thompson, J. K. (1996). Body image dissatisfaction in preadolescent children. Journal of Applied Developmental Psychology, 17, 85-100.

Yates, A., Edman, J., \& Aruguete, M. (2004). Ethnic differences in BMI and body/self-dissatisfaction among whites, Asian subgroups, Pacific islanders, and African-Americans. The Journal of Adolescent Health, 34, 300-307. doi:10.1016/j.jadohealth.2003.07.014. 